for control purposes. After grinding the calcined samples into powders, hydration tests were performed by placing the powders into a constant temperature and humidity (96\%) chamber for up to four hours. The hydration rate was calculated as the ratio of the weight gain after hydration to the original sample weight.

Hydration rates of $0.5 \%$ to $1.8 \%$ were obtained, with the lower hydration rates generally corresponding to a higher valency of the dopant. The researchers attribute these results to two phenomena. $\mathrm{Ca}^{2+}$ and $\mathrm{Mg}^{2+}$ vacancies formed by reactions with the dopants increase the surface energy and enhance the sintering process, leading to more dense powders. Also, the preferential formation of solid solutions involving high-valency dopants (such as $\mathrm{Ti}^{4+}$ ) with the more-easily hydrated $\mathrm{CaO}$ phase decreases the $\mathrm{Ca}^{2+}$ concentration, reducing the tendency to hydrate.

TIM PALUCKA

\section{Alex Zunger to Receive TMS 2001 John Bardeen Award}

Alex Zunger, NREL's Research Fellow and leader of the Solid State Theory group (Basic Sciences Center), is the recipient of the John Bardeen Award for the year 2001, presented by the Minerals, Metals, and Materials Society (TMS). He is cited for "his seminal contributions to the theoretical understanding and prediction of 'spontaneous ordering,' phase-stability, and electronic properties of semiconductor alloys; for the impact that this work has had on experimental studies of electronic materials, and for his continued leadership in the field.

This work centers around Zunger's pioneering seminal theoretical studies of "spontaneous ordering" in semiconductor alloys - a phenomenon whereby instead of appearing randomly, the atomic constituents of alloys (e.g., gallium and indium in gallium phosphide-indium phosphide) tend to order spatially in geometric arrangements that alter the electronic, transport, and optical properties of the material creating new, technologically significant functions. A more detailed description of this field appears in the group's web site at www.sst.nrel. gov/topics/alloy_order.html.

Zunger said that his work on this theoretical problem was done in collaboration with his postdoctoral fellows since 1983: J. Bernard, D. Laks, K. Mader, R. Magri, J.L. Martins, T. Mattila, A. Mbaye, R. Osorio, V. Ozolins, G.P. Srivastava, and D. Wood, as well as with his NREL associates L. Ferreira, S. Froyen, S.H.Wei, and S.B. Zhang. Zunger's other areas of interest include photovoltaic materials, the theory of semiconductor quantum-dots, and the theoretical design and predictions of stable crystal structures and phase-diagrams.

This award will be presented formally to Zunger at the 130th Annual TMS meeting on February 13, 2001, in New Orleans.

\section{Peppas Receives General Electric Senior Research Award}

Nicholas A. Peppas, the Showalter Distinguished Professor of Chemical and Biomedical Engineering in the School of Chemical Engineering at Purdue University, has been presented with the General Electric Senior Research Award at an awards ceremony held at the annual conference of the American Society for Engineering Education in St. Louis on June 21. He has been honored for fundamental and prolific contributions to polymer engineering and science, biomedical engineering, and pharmaceutical engineering. These contributions have provided insight into numerous engineering processes and applications and led to the development of new biomaterials and medical devices, including artificial vocal cords, contact lenses, linings for artificial hearts, artificial cartilage, a wide range of drug delivery devices, and the recently commercialized oral insulin delivery systems. Peppas was appointed to his current position in 1993, and has served on the faculty at Purdue since 1976.

\section{Johnson and MacChesney Receive International Ceramics Prize}

Scientists David Johnson and John MacChesney of Lucent's Bell Labs have received the International Ceramics Prize 2000 from the Academy of Ceramics at the Forum 2000 conference held in Maiori, Italy, in June. The award, which recognizes important contributions to ceramics research, cites MacChesney and Johnson's "outstanding contribution to sol-gel technology and its industrial application in the area of optical communications."

Johnson holds a PhD degree in ceramic science from Pennsylvania State University. He is also an adjunct professor of materials science at Stevens Institute of Technology, Hoboken, NJ. He is a Fellow of the American Ceramic Society and a member of the National Academy of Engineering, Materials Research Society, North American Thermal Analysis Society, American Association for the Advancement of Science, American Society of Materials International, and American Society for Testing Materials.
MacChesney holds a PhD degree from Pennsylvania State University and is an adjunct professor at Brown and Rutgers Universities, as well as the Kwangju Institute of Science and Technology in Korea. He was elected to the National Academy of Engineering in 1985. He is a Fellow of the American Ceramic Society.

\section{Nishizawa Receives IEEE Edison Medal}

Jun-Ichi Nishizawa, president of Iwate Prefectural University in Japan, has received the 2000 Institute of Electrical and Electronics Engineers (IEEE) Edison Medal at the annual IEEE Honors Ceremony on June 24 in Vancouver, BC, Canada. He is honored "for contributions to the materials science and technology and the invention of the static induction transistor."

Nishizawa has made significant contributions to materials science and technology, fiber optics, optical communications, and other areas. Early in his career, he developed the static induction transistor and the static induction thyristor (SIT) for high-power and high-frequency devices. To enhance the SIT's performance, Nishizawa established the Semiconductor Research Institute in Tohoku University, Japan, where he has been director since 1968. Among his contributions are work on the development of such semiconductor devices as the pin diode and photodiode, and the npin drift transistor.

Nishizawa is a Life Fellow of IEEE and a member of the Materials Research Society. He received his $\mathrm{BS}$ and $\mathrm{PhD}$ degrees from Tohoku University.

\section{Alexis Clare Receives 2000 Gottardi Prize}

Alexis G. Clare, associate professor of glass science in the School of Ceramic Engineering and Materials Science, has been awarded the Gottardi Prize by the International Commission on Glass (ICG) "for outstanding achievement in the field of glass research and development, teaching, writing, management, or commerce." She received the award during ICG's annual meeting in May in Amsterdam, The Netherlands.

Clare is director of the Alfred satellite of the National Science Foundation's Industry-University Center for Biosurfaces. She is a member and Fellow of the American Ceramic Society and the Society of Glass Technology. She received her BS degree in chemical physics and her $\mathrm{PhD}$ degree in physics, both from the University of Reading, England. 